\title{
Speeding up innovation in agricultural IT
}

\author{
Hannu E. S. Haapala \\ Agrinnotech, Kalevankatu, Seinajoki, Finland
}

\begin{abstract}
An OECD funded research was conducted where methods and processes for speeding up innovation in agriculture were assessed. A global web-based questionnaire was sent to experts in agricultural engineering, research, marketing, education and users of new technologies. Interviews of selected experts were done to deepen the analysis. The results show that considerable part of the relatively slow innovation comes from the fact that users do not trust in new technologies or that the usability of them is unacceptable. The experts suggest that education of the engineers and designers should include more elements from User-Centered Design (UCD) and also User-Driven Innovation methods should be more used. As a conclusion a new 'Dream Team' of agricultural innovation was developed where user interaction and marketing professionals were given more roles.
\end{abstract}

\section{Introduction}

An innovation, by definition, needs to be widely adopted by its users. The Oslo manual of innovation (OECD 2005) claims that technological innovations consist of implemented products and processes. The original definition of innovation by Schumpeter (1934, ref. Drejer 2004) claims that it is essential for an innovation that it is applied in practice. The definition also tells that users typically spread innovations through imitation. As the innovation is found useful, it finds new users. Consequently, because of this crucial role, the end-users should

Correspondence: Hannu Haapala, Agrinnotech, Kalevankatu 12b A26, 60100 Seinajoki, Finland.

Tel. +358400814808 .

E-mail: hannuhaapala1@gmail.com

Key words: innovation, agriculture, IT, User-Centered Design.

Acknowledgments: the author would like to thank OECD Co-operative Research Programme for the research fellowship, and IVIA, Spain for the possibility to stay as a visiting researcher during the project.

Contributions: the author is solely responsible for the entire work.

Funding: the work was supported by an OECD CRP (Co-operative Research Programme) Fellowship.

Conference presentation: part of this paper was presented at the CIGRAgEng 2012 Conference in Valencia, Spain, July 8-12, 2012 and AiiA13 Conference in Vitebro, Italy, September 8-12, 2013.

(c) Copyright H.E.S. Haapala., 2013

Licensee PAGEPress, Italy

Journal of Agricultural Engineering 2013; XLIV(s2):e26

doi:10.4081/jae.2013.s2.e26 be involved in the innovation process. In past decades, researchers and designers of agricultural technologies have created new ideas to meet the urgent global challenges in food, feed, fibre, and fuel production. Consequently, quite a few new technologies have been developed.

Precision Farming (PF) is a good example of this development. PF applies accurate control technologies to plant production. Measurement and control technologies enhance the efficiency and, simultaneously, reduce the negative impacts of production. The goal is to produce accurately according to the needs of the soil and plants, thus optimizing the use of inputs. (Haapala 1995). Uptake of PF technologies by the end-users, however, has not been very effective. As the adoption is weak, the technologies do not provide all their potential benefits. Only some individual technologies, such as row guidance and yield mapping, have been adopted in large farms (Diekman \& Batte 2010, Winstead et al. 2010). The vision of a fully integrated Precision Farming system (e.g. Haapala 1995) has not, however, been realised in such a magnitude that it could be called an innovation. As argued before, weak adoption stops the innovation process. That is true in the case of Precision Farming as well. If the PF technologies are not applied effectively and widely enough, the users get limited benefits and they eventually stop using PF. Generally, one evident reason for weak adoption is that potential users are conservative and do not trust enough in new technologies (Kaasinen 2005, Li et al. 2008). In order to be better adopted, the new technologies need to show remarkable benefits as compared to the old ones. Changing from old technologies has to be profitable. To be acceptable, they also need to be easy to learn, easy to use, dependable and ergonomically sound (Nielsen 1993). This is true also in agricultural technologies (Haapala \& Nurkka 2006). A successful innovation process can be divided in subsequent phases that all must be efficient (Haapala 2012a, 2012b). The technological level of the product must be at an appropriate level, the technology must be acceptable, and it has to be purchased and applied in a correct way. Furthermore, the volume of application has to be wide enough. In other words, the R\&D process must produce suitable technologies for the users and their needs, and the users must use the technologies in a correct way. Since the end-users are in a crucial role, User-Centered Design methods (UCD) can enhance the innovation process. UCD methods help to choose appropriate technological level of the product. Especially UCD enhances acceptability of the product. An acceptable product is more likely to become an innovation since it produces positive user experience that boosts the imitation process. Consequently, UCD enables the purchase and use of a new technology. (Haapala 212a, 212b). As derived above, UCD could help to design better tools for PF so that it could be better adopted and utilized by the end-users of these technologies. The goal of this research was to test this hypothesis. (Haapala 2012a, 2012b). End-users of technologies have a central role in Living Lab methodologies. In agricultural engineering Living Labs have been used for User-Centered RDI but also for education (Haapala \& Pasila 2008, 2009, Wolfert et al. 2010). Living Labs were included in this research as a potential realization of the UCD in agricultural engineering. 


\section{Materials and Methods}

The research was performed as a literature review, an internetbased Webropol ${ }^{\circledR}$ questionnaire for experts (sent to over 500 recipients, 341 opening the questionnaire, answering rate $12 \%$, resulting $\mathrm{N}=41)$ and interviews of selected experts $(\mathrm{N}=10)$. The recipients were from all continents except Africa.

Acceptability of PF technologies was evaluated in modified categories of Nielsen (1993). Some detailed features of economy, benefits and technical compatibility and reliability were added. The concept of trust was also added.

In the questionnaire, the PF technologies were split into classes related to field operations, planning and control, and quality aspects. The questionnaire had four topics: technological level of PF products, application rate of PF, acceptability of PF, and the applicability of UCD to $R \& D$ in agricultural engineering.

The experts used the same topics but additionally they gave their opinions and visions of the most important research and development topics of UCD in Agricultural Engineering. Finally, the experts evaluated pre-set arguments of the potential of User-Centered Design (UCD) in the agricultural innovation process. They also rated the importance and urgency of UCD and PF related actions in research policy.

\section{Results}

In every class of PF technologies, the experts would like the current level of technology to be better than it is. In other words, they were dis- appointed on the past development. However, they were optimistic about the future and believed that $R \& D$ will be capable to narrow the technological development gap. Some technologies, such as the measurement of weather parameters or yield quantity, are not expected to develop much until 2020. Most potential development is expected to be in the planning algorithms. (Haapala 2012b)

Also in the case of application rate of PF technologies the experts were not satisfied with the current situation. Nor did the experts believe that the future application rate of PF technologies meets the expectations. Most potential growth in application was expected to be in the measurement of plant parameters and in the development of Farm Management Information Systems (FMIS). (Haapala 2012b)

The experts argued that efficiency of use is the most important component in usability. Economic aspects including awareness of the costs and benefits are also significant. Reliability and trust building were also ranked high. (Haapala 2012b)

The experts agreed that the current innovation process is not perfect. The end-users are not adequately involved in the R\&D process and even if they are the designers do not understand them well enough. Experts think that UCD could bring more speed into the innovation process. However, the designers are not familiar with the UCD methods. There is an agreement among experts that UCD and related methods would yield to better products that would help the users to better adopt new technologies. Also trust in new technologies would be built with the use of UCD. (Haapala 2012b, Figure 1)

During the interviews of selected experts it became evident that the subject of the research was ranked as highly important. The interviews revealed a widespread concern on the situation in agricultural innovation processes. The interviewed experts agreed that the new technologies will not be applied enough if the user issues are ignored. The developers shoud know the user benefits in much more detail.

\section{Innovation process and UCD in Agricultural Engineering}
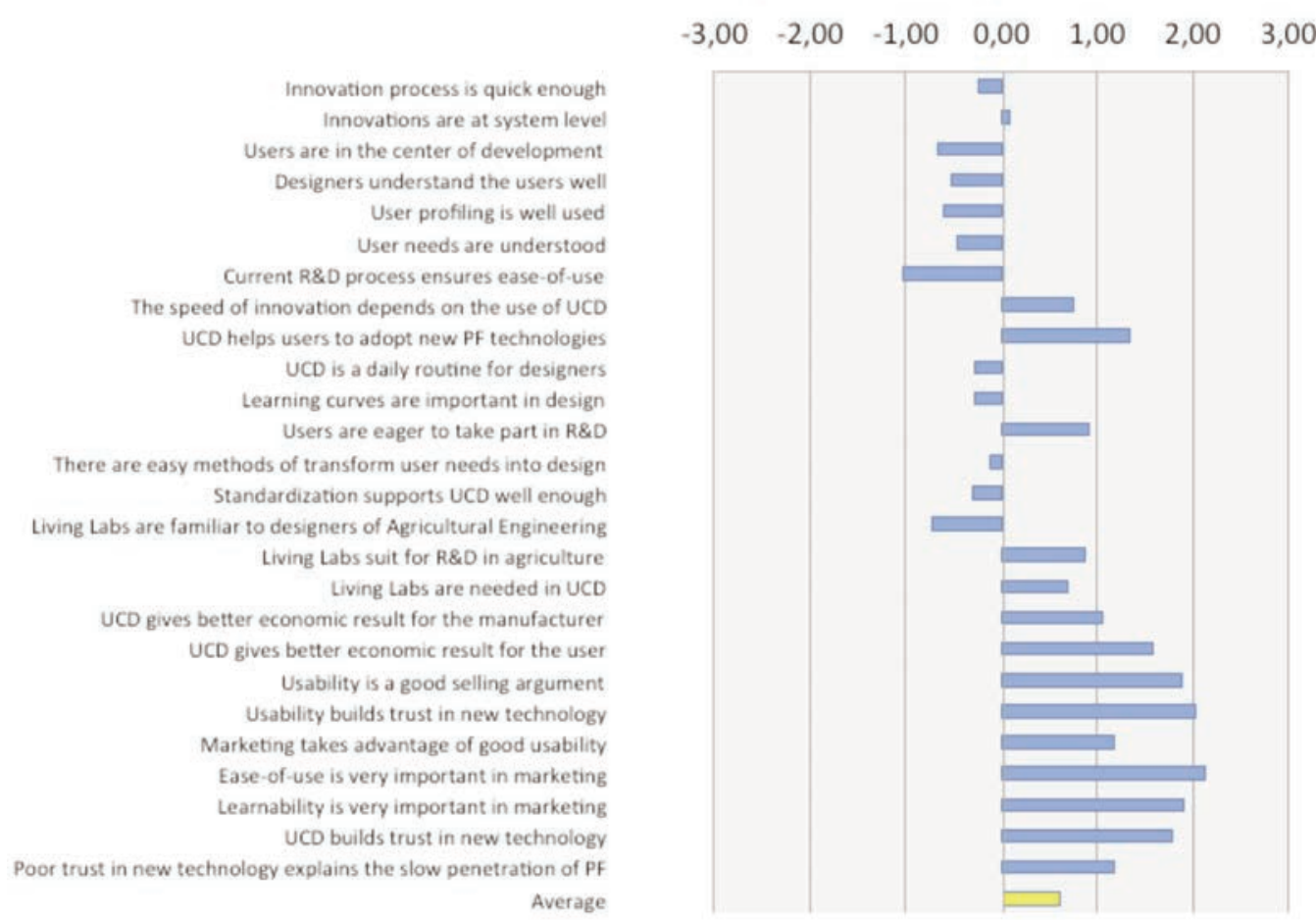

Figure 1. Innovation process and UCD in Agricultural Engineering. Arguments (-3=argee, $0=$ neutral, 3=agree). 
Concervatism of farmers was pointed out to be an important fact limiting risk taking. Marketers of agricultural technologies should be more integrated in the innovation process since they have much contact to the end-users so that they have the potential to enhance innovation. On the other hand, marketers need reliable information about customer benefits.

\section{Discussion}

The respondents' competence profile was variable. In general, they were strong in engineering, research and practical use of technologies at the farm level. They evaluated themselves to have weaknessess in skills considering marketing, sales and teaching of design.

According to the feedback received, the questionnaire was heavy (over 40 pages). This limited the number of recipients. On the other hand, the recipients who dedicated their time for the questionnaire felt that the questions were relevant for the research topic.

The literature review revealed that there has not been much research on the subject of acceptability of argicultural engineering. Comparable research has mainly been done in other industries (e.g. Nielsen 1993, Kaasinen 2005, Li et al. 2008). Comparison of the results is somewhat difficult since agriculture is a very seasonal profession. The processes that apply technologies are not continuous so that the technologies are used in short periods of time that occur only a couple of times during the year. The users of agricultural technologies are often different from other workers because of their comparably high middle age, low educational level and low motivation to use the latest developments.

\section{Conclusions}

The results show that, in order to increase the speed of innovation, the end-users of new sustainable production systems such as Precision Farming (PF) need to trust better in the technologies involved. Acceptable products increase adoption of new technologies in agriculture. A deeper involvement of end-users in the design process yields products that are more acceptable. Using User-Centered Design (UCD) methods shortens the design phase in R\&D because less iteration is needed to design an acceptable product. Therefore, UCD speeds up the innovation process. Since innovation is spread through imitation, the

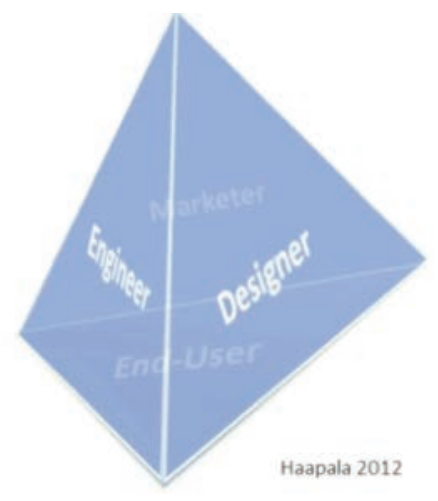

Figure 2. Innovation Dream Team. In addition to the traditional Enginee-Designer team the End-Users and Marketers of the technology should be integrated into the innovation process. lead users need to have good experiences of using new technologies. Consequently, Living Labs where the lead users act as developers could be used to efficiently spread the good image of UCD-designed products. In future, education of the engineers and designers in agricultural R\&D should include more elements from User-Centered Design (UCD) and also User-Driven Innovation methods should be more used.

The 'Dream Team' of agricultural innovation experts would consist of the traditional engineer-designer working partners but enhanced with the end-users and marketing specialists. This would add the needed user interaction and marketing expertise to the innovation process (Figure 2).

\section{References}

Diekmann, F. \& Batte, M. 2010 Ohio Farming Practices Survey: Adoption and Use of Precision Farming Technology in Ohio. Experimentation report AEDE-RP-0129-10. http://tiny.cc/Diekmann_Batte.

Drejer, Ina 2004. Identifying innovation in surveys of services: a Schumpeterian perspective. http://dx.doi.org/10.1016/j.respol.2003.07.004. In: Research Policy. Elsevier. Vol. 33, 3: 551-562.

Haapala, H. \& Nurkka, P. 2006. Usability as a Challenge in Precision Agriculture - case study: an ISOBUS VRT. Agricultural Engineering International: the CIGR Ejournal. 9 p.

Haapala, H. \& Pasila, A. 2008. Agro Living Lab as a Tool to Teach R\&D. 2008 ASABE Annual Meeting June 29 - July 2, 2008.

Haapala, H. \& Pasila. A. 2009. Agro Living Lab - an R\&D platform- ensuring acceptability of new technology among farmers. 67th International Conference on Agricultural Engineering LAND.TECHNIK AgEng 2009.

Haapala, H. 2012a. Speeding up innovation in agriculture. Questionnaire for Experts. Webropol questionnaire. http:/agrinnotech.com.46 p.

Haapala, H. 2012b. The potential of User-Centered Design (UCD) to make radical agricultural innovations. In: International Conference of Agricultural Engineering. CIGR-AgEng 2012. July 8-12. Valencia, Spain.

Kaasinen, E. 2005. User acceptance of mobile services - value, ease of use, trust and ease of adoption. Espoo 2005. VTT Publications 566. 151 p. + app. 64 p.

Li, W., Hess, T. \& Valacich, J. 2008. Why do we trust new technology? A study of initial trust formation with organizational information systems. The Journal of Strategic Information Systems. http://dx.doi.org/10.1016/j.jsis.2008.01.001. Elsevier. Vol 17, 1: 39-71

Nielsen, J. 1993. Usability Engineering. Academic Press Inc. 362 p.

OECD 2005. Oslo Manual. The measurement of scientific and technological activities. Proposed guidelines for collecting and interpreting technological innovation data. European Commission. Eurostat. www.oecd.org/sti/oslomanual. ISBN 978-92-64-01308-3. 3rd ed. 163 p.

Winstead, A., Norwood, S., Griffin, T., Runge, M., Adrian, A., Fulton, J. \& Kelton, J. 2010. Adoption and Use of Precision Agriculture Technologies by Practitioners. In: Proc.the 10th International Conference on Precision Agriculture, 18-21 July 2010. Denver, Colorado.

Wolfert, J., Verdouw, C., Verloop, C. \& Beulens, A. 2010. Organizing information integration in agri-food-A method based on a service-oriented architecture and livinglab approach. Special issue on Information and Communication Technologies in Bio and Earth Sciences. http://dx.doi.org/10.1016/j.compag.2009.07.015. Computers and Electronics in Agriculture. Elsevier. Vol. 70, 2: 389-405. 